\title{
INFLUENCE OF JUVENILE HORMONE ON GROWTH AND DIGESTION IN FIFTH INSTAR LARVAE AND ADULTS OF LOCUSTA MIGRATORIA
}

\author{
A. M. Th. BEENAKKERS and A. TH. M. VAN DEN BROEK \\ Laboratory of Chemical Animal Physiology, University of Utrecht, \\ 40 Jan van Galenstraat, Utrecht, The Netherlands
}

(Received 29 October 1973)

\begin{abstract}
Food utilization was measured in female fifth instar larvae and adults of the migratory locust by following the weight of food ingested, the weight of faeces produced, and the increase in body weight. These parameters were measured in normally developing locusts, in locusts that had been implanted with a pair of active corpora allata (CA) in the beginning of the fifth instar period, and in allatectomized locusts, operated on the first day after adult ecdysis.

A high titre of corpus allatum hormone results in a considerably higher water content of the insects; allatectomy reduces this content. The dry weight of the locusts is not essentially influenced by excess or absence of juvenile hormone.

Food consumption in corpora-allata-implanted locusts does not differ from that in normally developing insects. Within each developmental period the digestive capacity remains constant, but the absolute value of this capacity may differ between the two developmental periods. The approximate digestibility is somewhat higher after CA-implantation and lower after allatectomy. The efficiency of conversion of digested food into body substance is greater in normally developing larvae than in adults. CA-implantation lowers this efficiency in developing larvae. Allatectomy slightly raises the efficiency of conversion in adult locusts.

In the second half period of larval development, CA-implantation raises the respiratory rate, as estimated by measuring oxygen consumption. During adult development no significant influence of $\mathrm{CA}$-implantation on respiration was established. Relations between the amount of food digested, the efficiency of conversion of digested food into body substance, and the respiratory activity are discussed.
\end{abstract}

\section{INTRODUCTION}

RECENT work has provided data concerning growth and feeding activity in the migratory locust under different external conditions (BEENAKKERS et al., 1971). The present report deals with the influence of juvenile hormone (JH) on these physiological characteristics. Our investigations were performed in the scope of our experiments on the influence of endocrine organs on the development of internal organs, particularly the flight muscles (POELs and BEENAKKERS, 1969; BEENAKKERS, 1973). 
Data concerning the influence of $\mathrm{JH}$ on consumption and absorption of food in locusts are scarce and restricted to the adult growth period. HrLl et al. (1966) measured growth and faeces production in allatectomized female desert locusts; Oрніамво (1966), performing similar experiments on male desert locusts, used food intake as a parameter of the amount of metabolic material available, as did WALKER and BAILEY (1971), who, in contrast with the other authors, concluded that allatectomized insects consume more food than control specimens.

STRong $(1967,1968)$ estimated food consumption from the weight of faeces produced in allatectomized migratory locusts. Allatectomy had no apparent effects on feeding activity in males, and in allatectomized females the initial period of active faeces production, accompanying adult somatic growth, followed slightly after that in the operated controls.

None of these studies related growth to the actual amount of digested food. Moreover, faeces production or food intake can be taken as a reference for the metabolic material available for the insect only if throughout the adult (or any other) growth period a constant relationship exists between the amount of food digested and one of the two parameters mentioned. In normal development the digestibility remains constant during the adult growth period, as well as during the last larval instar (BEENAKKERS et al., 1971), although the approximate digestibility in the larvae reaches a higher value. MoRdue and HILL (1970) demonstrated a higher digestibility during adult somatic growth than during ovarian growth in Schistocerca. The present paper shows the results of experiments in which growth and digestion of the migratory locust during the last larval and adult somatic growth period are followed under the experimental conditions of allatectomy or implantation of extra corpora allata.

\section{MATERIALS AND METHODS}

The experiments were performed with female migratory locusts, Locusta migratoria migratorioides, reared in our laboratory under crowded conditions, at $311^{\circ} \mathrm{C}$, r.h. of about $40 \%$, and a mean natural photoperiod of $12 \mathrm{hr}$.

\section{Implantation of corpora allata $(C A)$}

The $C A$ used for implantation were taken from female adults, 18 days after emergence, by cutting of the dorsal part of the head and removing the $\mathrm{CA}$, which were collected in Ringer solution $\left(9 \cdot 15 \mathrm{~g} \mathrm{NaCl}, 0.2 \mathrm{~g} \mathrm{KCl}, 0.4 \mathrm{~g} \mathrm{CaCl}_{2} \cdot 6 \mathrm{H}_{2} \mathrm{O}\right.$, $0.606 \mathrm{~g}$ Tris, $5 \mathrm{mg}$ streptomycin, aqua dest. ad $1000 \mathrm{ml}$; adjustment to $\mathrm{pH} 7.5$ with $3 \mathrm{~N} \mathrm{HCl}$ solution) at $0^{\circ} \mathrm{C}$. Female fifth instar larvae, $0-24 \mathrm{hr}$ old, were anaesthetized with carbon dioxide applied for $1 \mathrm{~min}$. Two CA suspended in a small quantity of Ringer solution were injected with a glass needle between the first and second abdominal tergites. The wound was sealed with a mixture of paraffin-beeswaxcolophonium resin $(1: 3: 1, \mathrm{w} / \mathrm{w})$. Mortality rate was 10 per cent. The control insects were injected with an equal quantity of Ringer solution. Groups of CA- 
implanted and control locusts were kept separately in cages of $20 \times 22 \times 22 \mathrm{~cm}$. These experiments were carried out in September.

\section{Extirpation of corpora allata}

Allatectomy was performed on locusts within $32 \mathrm{hr}$ after adult emergence.

The locust was held rigid in a clamp as described by STAAL (1961) in such a way that the dorsal parts of the cervical membrane were exposed and stretched. In the middle of the membrane a small tear was made and the median cephalic airsac removed. By section of the nervi corporis allatum I and II each CA was removed. During the operation the interior of the head was perfused with sterilized Ringer solution. After the operation the head capsule and pronotum were replaced in their original position. Sham-operated insects were similarly treated, the CA being exposed, but not removed. All instruments used were disinfected with $70 \%$ alcohol. Postoperational mortality never exceeded 10 per cent.

In order to follow food comsumption and faeces production of the individual locusts, but nevertheless to maintain the crowded conditions as well as possible, the locusts were kept in rows of small cages $(8 \times 8 \times 9 \mathrm{~cm})$ separated from each other by walls of stainless steel wire netting (holes of $7 \times 7 \mathrm{~mm}$ ), resulting in a net open surface of 70 per cent. As the bottom of the cages consisted of perforated aluminium plate, the weight of the faecal pellets, as well as the amount of food eaten by each individual locust could be estimated. These experiments were performed in March.

\section{Measurements of growth and feeding activity}

Wet weight of the individual locusts was measured daily and at the same time each day, starting just before operation (excluding the first day after the operation in the allatectomy experiments). In another series of experiments wet and dry weights of CA-implanted, allatectomized, and sham-operated locusts were determined at 3 to 4 day intervals. These data were used for calculating the actual dry weight of the animals used in the feeding experiments.

Feeding activity was estimated as described by BEENakKkRs et al. (1971), measuring both the weight of the food consumed and the weight of the faeces produced. The locusts were fed with equal parts of wheat- and rye-leaves.

Data obtained in CA-implantation experiments refer to the results of two series, each series consisting of a sham-operated and an implanted group of 10 insccts. The experimental results after allatectomy refer to one series.

\section{Quantification of the feeding results}

In order to quantify the data obtained, the following indices were calculated: (a) approximate digestibility (AD), (b) efficiency of conversion of ingested food to body substance (ECI), (c) efficiency of conversion of digested food to body substance (ECD), (d) growth rate (GR) (cf. BeEnakkers et al., 1971). The indices were calculated on the basis of dry weight of both locusts, and food and faeces. 


\section{Respiration measurements}

Oxygen consumption of the CA-implanted and sham-operated locusts, performed every day at 15.00 p.m., was measured with the common Warburg technique. Locusts were placed in a cylinder of small-mesh wire netting in especially constructed flasks. Flask volume was either $25 \mathrm{ml}$ for measurements on larvae or $60 \mathrm{ml}$ for the adults.

The experimental temperature was $30^{\circ} \mathrm{C}$ and respiration was measured over a period of $30 \mathrm{~min}$. For trapping $\mathrm{CO}_{2} 1 \mathrm{ml} 15 \% \mathrm{KOH}$ solution was used. The animal volume, needed for calculation of the consumption, was determined by immersing 10 locusts in water and measuring the volume of the displaced water. Specific gravity of the larvae was $1 \cdot 0$, of the adults 0.75 .

Determinations of oxygen consumption were performed on 7 larvae and 5 adults.

\section{Implantation of corpora allata}

\section{RESULTS}

Morphology and ecdysis. The pronotum of the fifth instar larvae, injected with extra CA at the beginning of the instar period, showed a green pigmentation about 5 days after the operation. After the fifth ecdysis this pigmentation was visible all over the body surface, particularly on the dorsal parts of the head, thorax, and legs. The ecdysis resulted in metathelic or imperfect adults with unusually short wings. After about 2 weeks an extra apolysis occurred; during the subsequent ecdysis, however, all insects died. For the sake of convenience the fifth ecdysis will be referred to as the adult ecdysis as it is in normal development.

Under the environmental conditions described, the duration of the fifth instar period of normally developing locusts is 9 days, but that of CA-implanted locusts almost 1 day shorter. In order to compare the larval development in both control and CA-implanted locusts, the fifth instar period is stated as 100 per cent.

\section{Somatic growth}

Fig. 1 shows the changes in somatic wet and dry weights of control and CAimplanted locusts during the experimental period; already soon after the operation feeding activity starts and insect weight increases. During the larval period wet and dry weights increase considerably (Table 1); the increase in the sham-operated and CA-implanted larvae does not differ significantly.

In control insects the larval-adult ecdysis is accompanied by a considerable loss of water, whereas after CA-implantation no decrease in wet weight was demonstrated. Dry weights of both groups remain about the same during the transition from larva to adult. The difference in loss of water between the normal and CA-implanted locusts may be due partly to differences in evaporation and partly to differences in the consumption level around the moment of ecdysis. After the larval-adult ecdysis the dry weights of experimental and control locusts increase at about the same rate, but, particularly in the second half of the adult growth period, the CA-implanted locusts retain more water than the sham-operated insects. This must be the consequence of greater water loss during normal development, as in the 
CA-implanted locusts the water content remains \pm 75 per cent of the body weight, whereas in the sham-operated specimens it decreases from 76 to 67 per cent of the total weight.

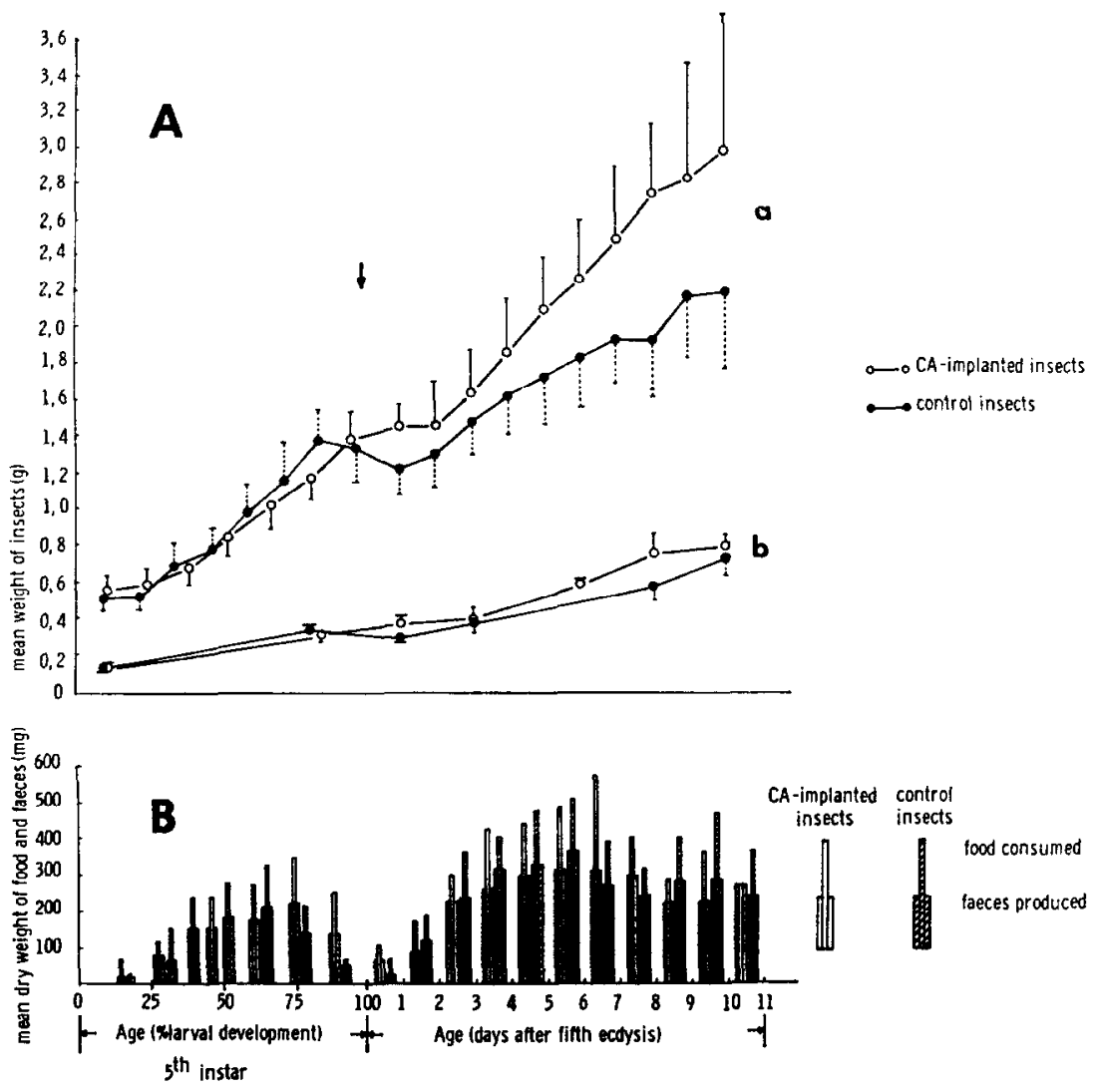

Fig. 1. Growth and feeding activity of normally developing and CA-implanted female locusts during fifth larval instar and adult somatic growth period. (A) Changes in wet weight (a) and dry weight (b) during development. The arrow indicates the moment of metamorphosis. (B) Food consumption and faeces production, expressed as the daily amounts per insect.

\section{Feeding activity}

The effects of CA-implantation on the feeding behaviour are shown in Fig. 1. In the larvae food consumption is high at about 70 per cent of larval development, it then decreases quickly in the controls and more slowly in the implanted locusts; even in the days around the imaginal moult these insects eat a fair amount. The total amount of food consumed during larval development is about the same in both groups, which is also true for the amount of digested nutrients (Table 1). Also in the adult growth period both groups consume as well as absorb about equal amounts of food. 
Table 1-Growth, CONSUMPtion, and Digestion of Control and CA-implanted FEMALE LOCUSTS

\begin{tabular}{|c|c|c|c|c|}
\hline & \multicolumn{2}{|c|}{ Control insects } & \multicolumn{2}{|c|}{ CA-implanted insects } \\
\hline & Larvae & Adults & Larvae & Adults \\
\hline \multicolumn{5}{|l|}{ Insect wet weight (g) } \\
\hline Minimal & 0.51 & $1 \cdot 20$ & 0.56 & 1.45 \\
\hline Maximal & $1 \cdot 36$ & $2 \cdot 18$ & 1.38 & 2.96 \\
\hline Weight gain & 0.85 & 0.98 & 0.82 & $1 \cdot 51$ \\
\hline \multicolumn{5}{|l|}{ Insect dry weight (g) } \\
\hline Minimal & $0 \cdot 12$ & 0.29 & $0 \cdot 14$ & $0 \cdot 36$ \\
\hline Maximal & $0 \cdot 35$ & 0.72 & $0 \cdot 36$ & 0.78 \\
\hline Weight gain & 0.23 & 0.43 & $0 \cdot 22$ & $0 \cdot 42$ \\
\hline \multicolumn{5}{|l|}{ Dry weight $(\mathrm{mg})$ of } \\
\hline Food consumed & 1359 & 3855 & 1403 & 3713 \\
\hline Faeces & 830 & 2670 & 827 & 2515 \\
\hline Food digested & 529 & 1185 & 576 & 1198 \\
\hline
\end{tabular}

\section{Utilization of the food}

Table 2 shows the AD, ECI, ECD, and GR values during the fifth larval instar and during the adult somatic growth period.

The GR of the larvae is much higher than the GR of the adults. CA-implantation does not influence this rate.

TAble 2-Utilization data of foon in larvak and adults of control and CA-IMPLANTED LOCUSTS

\begin{tabular}{clcccc}
\hline Developmental stage & \multicolumn{1}{c}{ Treatment } & AD & ECI & ECD & GR \\
\hline \multirow{2}{*}{ Fifth instar } & Control & 39 & 17 & 43 & $0 \cdot 16$ \\
\multirow{3}{*}{ Adult } & CA-implantation & 41 & 15 & 37 & $0 \cdot 16$ \\
& Control & 31 & 11 & 36 & $0 \cdot 10$ \\
& CA-implantation & 32 & 11 & 35 & $0 \cdot 08$ \\
\hline
\end{tabular}

During each of the two developmental periods investigated the sham-operated locusts show a constant $\mathrm{AD}$, but with a higher value in the larvae than in the adults; this indicates that larvae have a greater digestive efficiency. During the whole experimental period $\mathrm{CA}$-implanted locusts have a somewhat higher $\mathrm{AD}$ than control insects (Table 2, Fig. 4a, b).

In control larvae the ECI and ECD are higher than in the implanted larvae. Thus during larval development in the latter insects a smaller proportion of the digested food is assimilated into the body tissues. The ECD in the implanted adults does not differ from the ECD in the implanted larvae, in contrast with corresponding data from sham-operated specimens. 


\section{Respiration}

Fig. 2 shows the oxygen consumption during the larval and the adult growth period. After the fourth ecdysis oxygen consumption rises quickly; in shamoperated animals respiration decreases again in the last days before the larval-adult ecdysis. In CA-implanted locusts, however, the respiration rate remains high

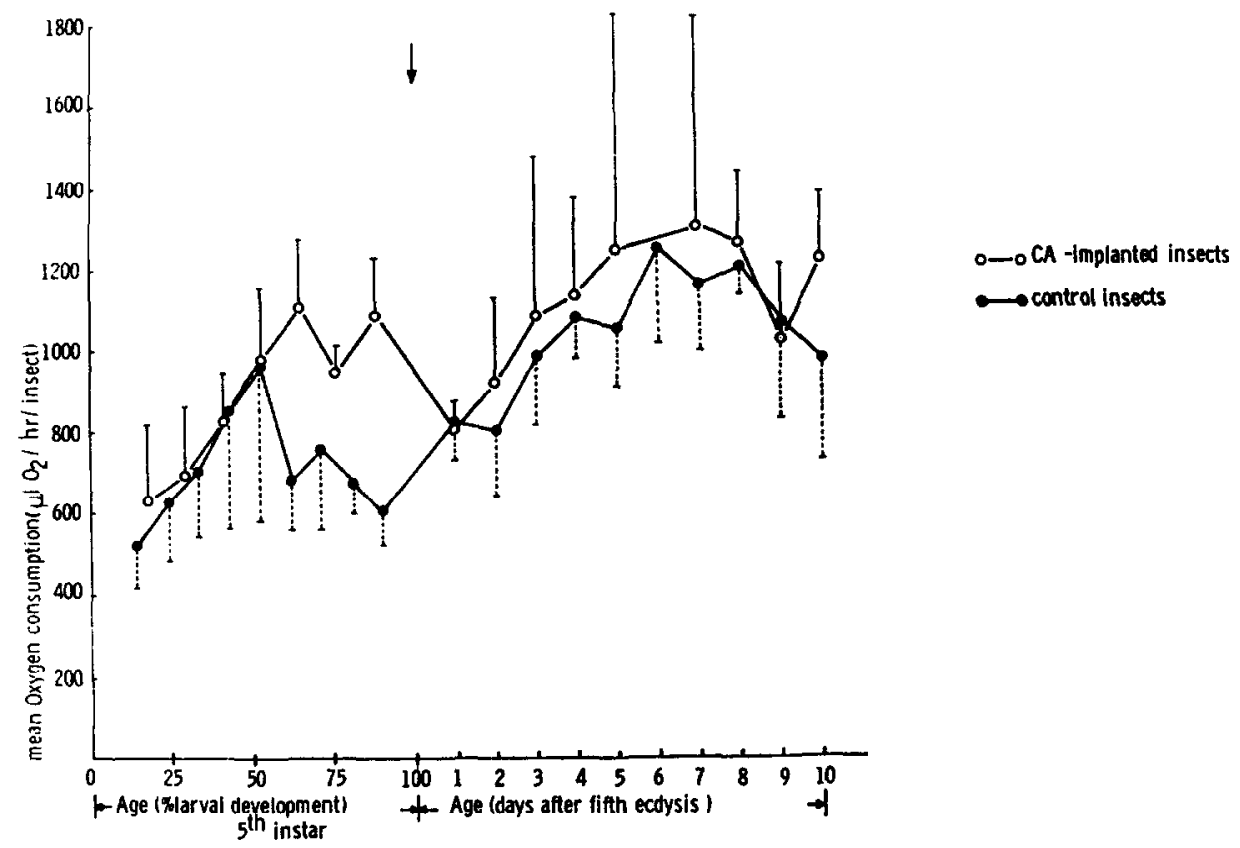

Fig. 2. The mean oxygen consumption of CA-implanted and control locusts during development. Respiration was measured once a day during $30 \mathrm{~min}$ in 'resting' locusts. The arrow indicates the moment of metamorphosis.

during the second half of the larval developmental period at a value that is statistically different from normal rates. After the adult ecdysis the respiratory rates of both CA-implanted and sham-operated locusts are essentially identical, reaching their highest values at about day 7 .

\section{Extirpation of corpora allata}

Growth. Fig. 3 shows the changes in somatic wet weight of the allatectomized locusts in comparison with sham-operated insects during about 2 weeks of adult life.

Although accidentally starting at a somewhat higher mean wet weight, the final wet weight of the allatectomized locusts is lower than that of the shamoperated animals. This is entirely due to differences in water content as gain in dry weight in both groups is similar (Table 3). Thus the GR values shown in Table 4 are almost identical, in spite of the fact that in the allatectomized insects egg 
development was inhibited, a process that in normal locusts under our experimental conditions begins at about day 10 . As a matter of fact, substrates for yolk deposition are mainly derived from the fat body: 16 days after the imaginal moult the dry

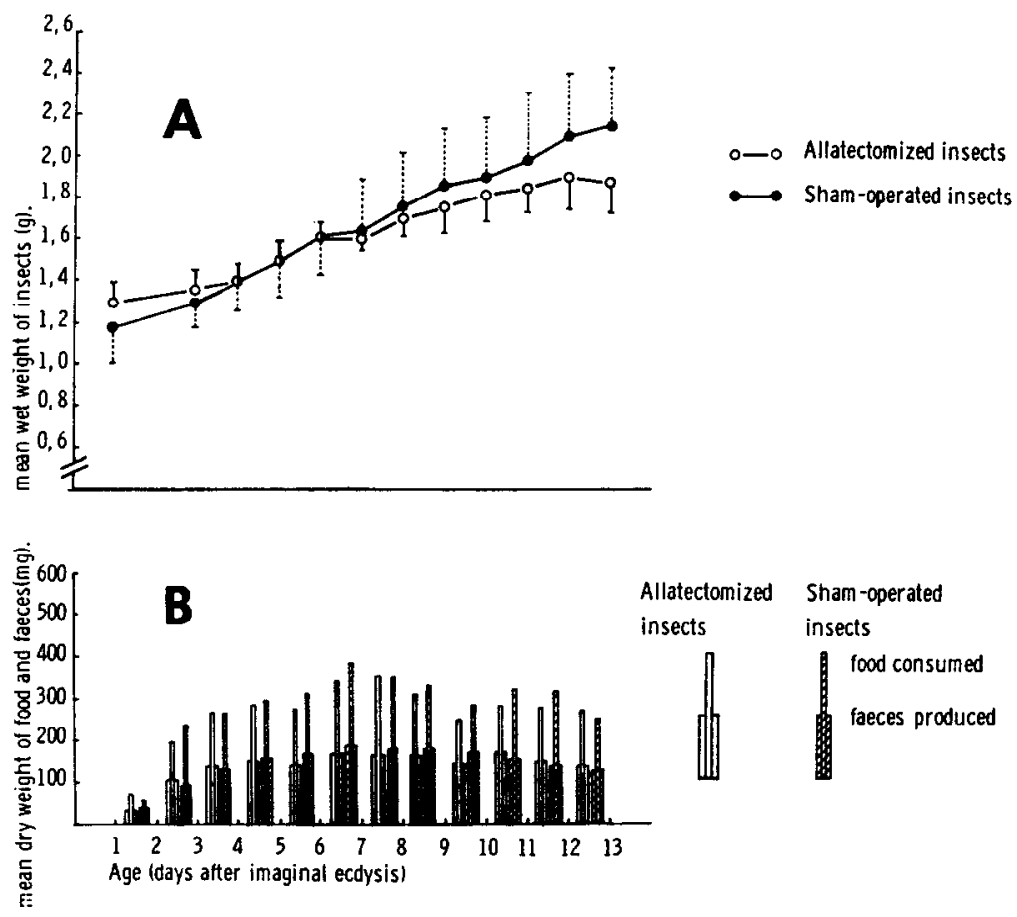

FIG. 3. Growth and feeding activity of normally developing and allatectomized female locusts during adult somatic growth. (A) Changes in wet weight. (B) Food consumption and faeces production, expressed in the daily amounts per insect.

Table 3-Growth, Consumption, AND Digestion of SHam-OPERATED AND ALLATECTOMIZED FEMALE ADULTS OF Locusta

\begin{tabular}{lcc}
\hline & $\begin{array}{c}\text { Control } \\
\text { insects }\end{array}$ & $\begin{array}{c}\text { Allatectomized } \\
\text { insects }\end{array}$ \\
\hline $\begin{array}{l}\text { Insect wet weight (g) } \\
\quad \text { Minimal }\end{array}$ & $1 \cdot 16$ & $1 \cdot 30$ \\
$\quad$ Maximal & 2.08 & 1.89 \\
$\quad$ Weight gain & 0.92 & 0.59 \\
Insect dry weight (g) & & \\
$\quad$ Minimal & 0.33 & 0.37 \\
$\quad$ Maximal & 0.73 & 0.76 \\
$\quad$ Weight gain & 0.40 & 0.39 \\
Dry weight (mg) of & & \\
$\quad$ Food consumed & 3385 & 3141 \\
$\quad$ Faeces & 1664 & 1620 \\
$\quad$ Food digested & 1721 & 1521 \\
\hline
\end{tabular}


weight of the fat body in the allatectomized locusts was $110 \mathrm{mg}$ and in the shamoperated insects only $38 \mathrm{mg}$, whereas the dry weight of the developing eggs in these insects was $126 \mathrm{mg}$ (BERNAKKERS and VAN DEN BROEK, unpublished observations). So, generally speaking, not the entire, but the main part of the egg material is merely the result of an internal shift of body substance.

\section{Feeding activity and utilization of the food}

The daily amounts of food consumed and faeces produced are shown in Fig. 3. There is a great resemblance between the feeding activity patterns of allatectomized and sham-operated locusts: increasing activity in the first week after the operation, decreasing again in the second week. Calculated over the total experimental period, the sham-operated locusts eat more than the allatectomized (Table 3).
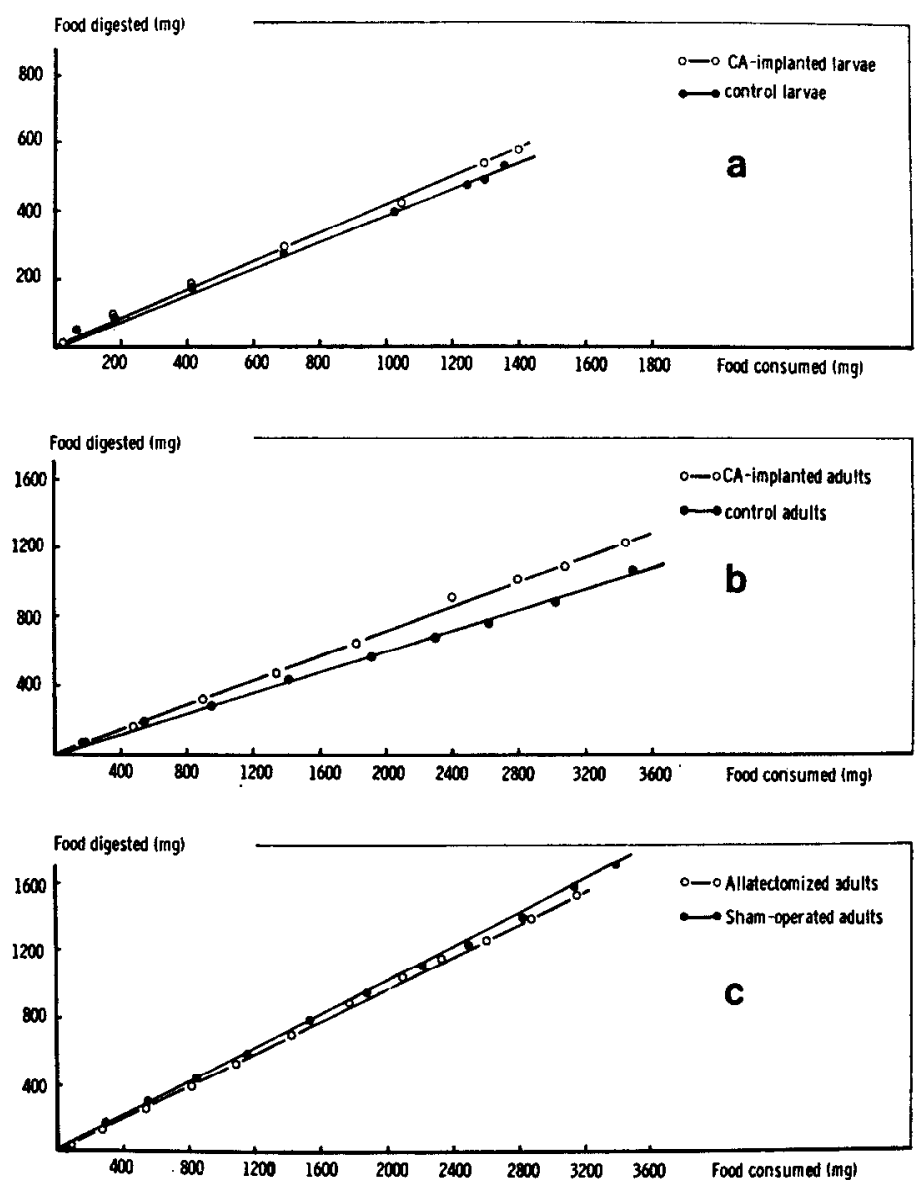

FIG. 4. The influence of CA-implantation during fifth larval instar (a), during the adult somatic growth period (b), and the influence of allatectomy (c) on the approximate digestibility during development of the locust. Amounts of food digested plotted vs. amounts of food consumed, expressed as mg dry weight. 
In both groups no change in the $\mathrm{AD}$ was demonstrated during adult development (Fig. 4c), but in the sham-operated locusts the AD was consistently slightly higher than in the allatectomized insects (Table 4). As a result of these phenomena, the amount of nutrients actually absorbed by the control locusts exceeds that of the allatectomized by $200 \mathrm{mg}$.

\section{TABle 4-UTilization Data OF FOOD IN SHAM-OPERATEd aND ALlatectomized FEMALE ADULTS OF Locusta}

\begin{tabular}{lcccc}
\hline Treatment & AD & ECI & ECD & GR \\
\hline Control & 51 & 12 & 23 & 0.07 \\
Allatectomy & 48 & 12 & 26 & 0.06 \\
\hline
\end{tabular}

The ECD in the allatectomized locusts is somewhat higher than in the controls, indicating that in the former group a greater proportion of the digested food is assimilated into the body tissues.

\section{DISCUSSION}

Our experiments indicate that $\mathrm{JH}$ promotes water retention in the locust. Implantation of extra $\mathrm{CA}$ decreases water loss during somatic growth, as was also shown by PoEls and BEENAKKERS (1969); allatectomy results in a lower insect wet weight, although dry weight is not influenced. Strong (1968) also showed a decrease in water content in allatectomized male migratory locusts. So the two opposite operations: extra implantation of CA and allatectomy have the opposite effect upon the water content. In our experiments both operations did not influence dry weight.

There is another phenomenon in which excess and absence of juvenile hormone have opposite effects. The AD in CA-implanted locusts is continuously a little higher, but in allatectomized animals it is constantly lower than in sham-operated specimens. So it can be suggested that the hormone (whether directly or indirectly) slightly raises the digestive efficiency. In this respect it can be noted that DAvEY (1954) demonstrated a decline in the AD with age from the first to the fifth instar of Schistocerca. In the same species MoRdue and HiLl (1970) demonstrated that during ovarian growth the $\mathrm{AD}$ is lower than during somatic growth; this does not support our idea of a decisive influence of $\mathrm{JH}$ on digestive efficiency.

The different absolute values of the AD between the sham-operated locusts in our implantation and our extirpation experiments must be the result of either differences in the physiological state of the insects (implantation experiments were performed in September, allatectomy in March), or in the composition of the food, that had been grown outdoors in September and in greenhouses in March; food grown outdoors may contain more indigestible material, resulting in a lower AD.

The diagrams of the $A D$ value in the various experiments are straight lines, indicating that during a certain developmental stage the digestive capacity remains 
unaltered. This has been demonstrated already for normally growing locusts (BEENAKKERS et al., 1971) and can now be extended for allatectomized or CAimplanted specimens too. Thus under these experimental conditions faeces production or food intake may be used as a parameter for the amount of food actually digested. It must be taken into account, however, that fifth instar larvae have an $\mathrm{AD}$ that is different from the $\mathrm{AD}$ in adults.

After CA-implantation the transition of larval to adult form is accompanied by only small, if any, changes in the wet and dry weights of the insects, a relatively high feeding activity, and a virtually steady respiratory rate; these phenomena suggest that both apolysis and ecdysis have less influence on the state of these insects than they have during normal development.

In adults of Schistocerca Hill et al. (1966) and OdHIAmBo (1966) showed that allatectomy does not affect the normal feeding pattern. In male adults of Locusta faeces production was not influenced by allatectomy (STRONG, 1968); operated females, however, showed a reduced feeding activity (STRONG, 1967). In our experiments both food intake and the amount of food digested were lower in allatectomized female adults than in sham-operated locusts.

There has to be a fundamental relation between the amount of food digested, the $\mathrm{ECD}$, and the respiratory activity. In our experiments, $\mathrm{CA}$-implanted larvae have a lower ECD than control larvae, indicating that after CA-implantation a smaller proportion of the food is used as tissue material. Larvae of both groups absorb about equal amounts of food. Consequently in the CA-implanted larvae a greater proportion of the digested food must be metabolized for energy production. We did not investigate the oxygen consumption during total larval and adult growth; our measurements were limited to one half hour a day on 'resting' locusts. In spite of that, CA-implanted fifth larvae did indeed show a significantly higher respiratory rate at least in the second half of larval development. Moreover, during adult development, in which both experimental and control groups absorbed equal amounts of food, almost identical ECD values were accompanied with equal oxygen consumption rates.

Acknowledgement-The respiratory measurements were carried out by Mr. E. V. M. BRouwERs and his contribution is greatfully acknowledged.

\section{REFERENCES}

BeENAKkers A. M. T. (1973) The influence of corpora allata on flight muscle development in locusts. F. Endocr. 57, 52.

Beenakkers A. M. T., Meisen M. A. H. Q., and Scheres J. M. J. C. (1971) Influence of temperature and food on growth and digestion in fifth instar larvae and adults of Locusta. 7. Insect Physiol. 17, 871-880.

Davey P. M. (1954) Quantities of food eaten by the desert locust, Schistocerca gregaria (Forsk.), in relation to growth. Bull. ent. Res. 45, 539-551.

Hill L., Mordue W., and Highnam K. C. (1966) The endocrine system, frontal ganglion, and feeding during maturation in the female desert locust. $\mathcal{F}$. Insect Physiol. 12, 11971208. 
A. M. Th. Bernakkers and A. Th. M. van den Broek

Mordue (Luntz) A. J. and Hill L. (1970) The utilization of food by the adult female desert locust, Schistocerca gregaria. Entomologia exp. Eீ appl. 13, 352-358.

Odhiambo T. R. (1966) Growth and hormonal control of sexual maturation in the male desert locust (Schistocerca gregaria Forskäl). Trans. R. ent. Soc. Lond. 118, 393-412.

Poels C. L. M. and BeEnakkers A. M. Th. (1969) The effects of corpus allatum implantation on the development of flight muscles and fat body in Locusta migratoria. Entomologia exp. \& appl. 12, 312-324.

Staal G. B. (1961) Studies on the physiology of phase induction of Locusta migratoria migratorioides R. \& F. Thesis, Wageningen.

SrRoNG L. (1967) Feeding activity, sexual maturation, hormones, and water balance in the female African migratory locust. F. Insect Physiol. 13, 495-507.

STRONG L. (1968) The effect of enforced locomotor activity on lipid content in allatectomized males of Locusta migratoria migratorioides. F. exp. Biol. 48, 625-630.

WALKER P. R. and BaILEY E. (1971) Effect of allatectomy on the growth of the male desert locust during adult development. F. Insect Physiol. 17, 1125-1137. 